Original Research Article

\title{
The study of skeletal muscle relaxant property of pheniramine maleate in acetylcholine induced contractions on isolated frog rectus muscle
}

\author{
Supriya Priyambada, Lakshmi Deepika P.*, Singamma M.
}

\begin{abstract}
Department of Pharmacology, Dr. PSIMS \& RF, Chinnaoutpalli, Andhra Pradesh, India
\end{abstract}

Received: 27 December 2017 Accepted: 29 January 2018

*Correspondence to:

Dr. Lakshmi Deepika P., Email: dreamangles.deepu@ gmail.com

Copyright: (C) the author(s), publisher and licensee Medip Academy. This is an openaccess article distributed under the terms of the Creative Commons Attribution NonCommercial License, which permits unrestricted noncommercial use, distribution, and reproduction in any medium, provided the original work is properly cited.

\begin{abstract}
Background: A muscle relaxant is a drug which affects skeletal muscle function and decreases the muscle tone. It may be used to alleviate symptoms such as muscle spasm, pain and hyperreflexia. Skeletal muscle relaxants are heterogeneous group of medications that refer to 2 major therapeutic groups: neuromuscular blockers and spasmolytics. This study is carried out to evaluate the skeletal muscle property of Pheniramine maleate in Acetylcholine Induced Contractions on Isolated Frog Rectus Muscle.

Methods: There are various screening techniques available to assess the muscle relaxant property of a drug. For initial screening, frog rectus muscle is used. Here frogs are divided into 4 different groups. Each group contains 6 isolated frog rectus muscles. The experiment is carried out by adding $100 \mu \mathrm{g}, 200 \mu \mathrm{g}, 400 \mu \mathrm{g}$ and $800 \mu \mathrm{g}$ of pheniramine maleate with $80 \mu \mathrm{g}$ of acetylcholine to the organ bath and response is recorded by kymograph.

Results: Pheniramine maleate in various doses like $100 \mu \mathrm{g}, 200 \mu \mathrm{g}, 400 \mu \mathrm{g}$ and $800 \mu \mathrm{g}$ with $80 \mu \mathrm{g}$ of acetylcholine $100 \mu \mathrm{g}$ showed the maximum contractions of frog rectus muscle in kymograph. At all the doses of Pheniramine maleate, it showed a significant effect of skeletal muscle relaxant property.

Conclusions: In conclusion with work done by using pheniramine maleate in different doses along with $80 \mu \mathrm{g}$ of acetylcholine. Pheniramine maleate showed the maximum skeletal muscle relaxant property on frog rectus muscle at $800 \mu \mathrm{g}$ dose.
\end{abstract}

Keywords: Isolated frog rectus muscle, Pheniramine maleate, Skeletal muscle relaxant property

\section{INTRODUCTION}

Skeletal muscle contraction and relaxation is regulated by neuromuscular junction (JMN) at the muscle end plate. Skeletal muscle relaxants are the group of drugs which affects skeletal muscle function and decreases the muscle tone. The term "muscle relaxant" is used to two major therapeutic groups: neuromuscular blockers and spasmolytics. They are used to treat two different types of underlying conditions.

- $\quad$ Spasticity from upper motor neuron syndromes
- Muscular pain or spasms from peripheral musculoskeletal conditions. ${ }^{1}$

The first muscle relaxant drug is identified in early 16 century by European explorers who encountered natives of the Amazon Basin in South America using poison tipped arrows that produced death by skeletal muscle paralysis. This poison is known today as curare. It is an active ingredient, d-tubocurarine which played a significant role in scientific experiments to determine the functions of Acetylcholine in neuromuscular transmission., ${ }^{2,3}$ 
Spasticity is a state of increased muscular tone with exaggeration of the tendon reflexes. Some of the common conditions associated with it include multiple sclerosis, spinal cord injury, traumatic brain injury, cerebral palsy and post stroke syndrome. Baclofen, Dantrolene and Tizanidineare approved for the treatment of spasticity.

Muscle spasm is defined as a sudden involuntary contraction of one or more muscle groups and is usually an acute condition associated with muscle strain (partial tear of a muscle) or sprain (partial or complete rupture of a ligament). ${ }^{4}$ Common musculoskeletal conditions causing tenderness and muscle spasms include fibromyalgia, tension headaches, myofascial pain syndrome and mechanical low back pain or neck pain. Carisoprodol, Chlorzoxazone, Cyclobenzaprine, Metaxalone, Methocarbamol and Orphenadrine are approved for the treatment of musculoskeletal disorders. ${ }^{5,6}$

Pheniraminemalaete is an antihistamine with anticholinergic properties used to treat allergic conditions such as hay fever or utricaria. ${ }^{7}$ Antihistamines are a diverse group of compounds comprising of phenothiazines, ethanolamines and ethylene diamines etc., It acts by inhibiting histamine release from human mast cells. ${ }^{8}$ In the present study, authors are trying to evaluate the Skeletal Muscle Relaxant Property of Pheniramine maleate and dose dependent effect of it in acetylcholine induced frog rectus muscle experiment. ${ }^{9,10}$

According to many studies done by Acharya and Rao, this work was undertaken to find the effect of antihistamine pheiramine maleate on skeletal muscle in different doses.

\section{METHODS}

There are various screening techniques available to assess the muscle relaxant property of a drug. For initial screening, frog rectus muscle technique is used. This study is carried out in the department of Pharmacology in Dr, Pinnameneni Siddhartha Institute of Medical Sciences and Research Foundation.

The animals used for the study are frog (Rana tigrana) rectus muscle. The frogs are divided into 4 different groups. Each group contains 6 isolated frog rectus muscles. The experiment is carried out by adding $100 \mu \mathrm{g}$, $200 \mu \mathrm{g}, 400 \mu \mathrm{g}$ and $800 \mu \mathrm{g}$ of pheniramine maleate with $80 \mu \mathrm{g}$ of acetylcholine to the organ bath and response is recorded by kymograph.

\section{Chemicals}

- Acetyl choline

- Pheniramine maleate

- Double distilled water

- Frog ringer solution

- Ringer composition: $\mathrm{NaCl}, \mathrm{KCl}, \mathrm{CaCl}_{2}, \mathrm{NaHCo}_{3}$, $\mathrm{NaH}_{2} \mathrm{Po}_{4}$, glucose, distilled water

\section{Equipment}

$\begin{array}{ll}\text { - } & \text { Kymogram } \\ \text { - } & \text { Tuberculin syringes } \\ \text { - } & \text { Glass beaking jar } \\ \text { - } & \text { Weighing balance } \\ \text { - } & \text { Thread and Needle } \\ \text { - } & \text { Stop watch } \\ \text { - } & \text { Organ bath } \\ \text { - } & \text { Aerator } \\ \text { - } & \text { Glass rod } \\ \text { - } & \text { Dissection box }\end{array}$

\section{Isolated frog rectus muscle experiment}

Study of the muscle contraction and relaxation property, frog rectus muscle is used. First, frog was rendered unconscious by pithing (i.e., by destroying the brain) and the skin of the anterior abdominal wall was cut by a midline incision and then it was cut laterally to expose the anterior abdominal wall frog dissection is done. The muscles were cut across just above the sternum at its base and the pair of muscles attached to it was dissected and rectus abdominus muscle is separated and quickly transferred into the petri plate containing ringer solution. The muscles were then carefully cleaned and one of them was trimmed to the desired size and mounted in an organ bath filled with ringer solution at room temperature and aerated by stream of fine bubbles emerging near the bottom of the bath. The pubic end is tied to the hook of aeration tube and transferred to organ bath. Air is supplied to tissue through aeration tube by slow bubbling. Tie the other end to the lever. Stabilize the tissue for 30minutes. The speed of the kymogram drum is maintained at $0.12 \mathrm{~mm} / \mathrm{sec}$. Baseline is taken for $30 \mathrm{sec}$ and $80 \mu \mathrm{g}$ of acetylcholine is added to the muscle, response is recorded for 90 seconds. The muscle is relaxed for $2-3 \mathrm{~min}$ by giving 2-3 washes. The cycle length of 5minutes is kept constant throughout the experiment. After recording the graded responses to different doses of pheniramine maleate, their effects upon acetylcholine induced contractions was studied. ${ }^{11}$

\section{RESULTS}

In this study, authors have tried to evaluate and compare the skeletal muscle relaxant property of Pheniranmine maleate in acetylcholine induced frog rectus muscle. The below given figures I and II shows the worked done by using the kymogram with frog rectus muscle on smoked drum by using glazed paper.

Both the Figures 1 and 2, show the graded dose responses of pheniramine maleate with acetylcholine induced frog rectus muscle at increasing doses of test drug by simultaneous contraction and relaxation of muscle. As seen in the graph, there is gradual decrease in the contractions of muscle by increasing doses. 
As shown in Table 1, it was taken four different doses of test drug $100 \mu \mathrm{g}, 200 \mu \mathrm{g}, 400 \mu \mathrm{g}$ and $800 \mu \mathrm{g}$ of pheniramine maleate with $80 \mu \mathrm{g}$ of acetylcholine. The height of contractions of frog rectus is taken and the mean of each group is calculated.

So, according to the values given in the table i.e., the height of contractions of rectus muscle, the relaxant property of phaniramine is more at $800 \mu \mathrm{g}$ when compared to the other doses.
Figure 2 shows the comparison of the mean heights of contractions of frog rectus muscle at $100 \mu \mathrm{g}, 200 \mu \mathrm{g}, 400 \mu \mathrm{g}$ and $800 \mu \mathrm{g}$ doses by taking test doses on $\mathrm{X}$-axis and mean height contractions of frog rectus on acetylcholine induced frog rectus muscle on Y-axis. According to the given graph, the contractions of muscle are more at $100 \mu \mathrm{g}$ dose and then it is gradually decreased.

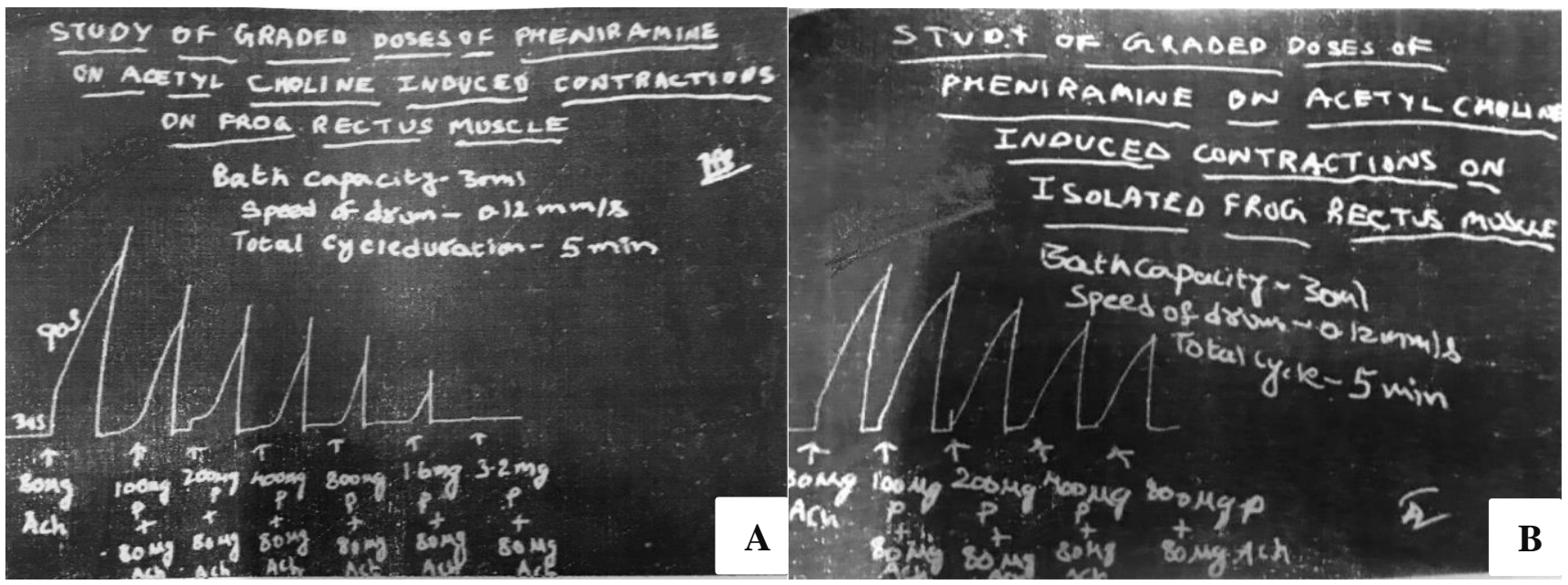

Figure 1 (A and B): The graded doses responses of pheniramine on acetylcholine induced contractions on isolated frog rectus muscle.

Table 1: Effect of pheniramine maleate on frog rectus muscle.

\begin{tabular}{|c|c|c|c|c|c|c|c|c|}
\hline S. No. & Drug conc. treatment & 1 & 2 & 3 & 4 & 5 & 6 & Mean \\
\hline 1. & Drug100 $\mu \mathrm{g}+\mathrm{ACh} 80 \mu \mathrm{g}$ & 5.3 & 5.3 & 2.6 & 2.9 & 3.3 & 3.2 & 3.77 \\
\hline 2. & Drug $200 \mu \mathrm{g}+\mathrm{ACh} 80 \mu \mathrm{g}$ & 4.8 & 5.1 & 2.8 & 2.3 & 2.9 & 2.7 & 3.43 \\
\hline 3. & Drug $400 \mu \mathrm{g}+\mathrm{ACh} 80 \mu \mathrm{g}$ & 4 & 4.9 & 2.1 & 1.8 & 2.3 & 2.3 & 2.9 \\
\hline 4. & Drug $800 \mu \mathrm{g}+\mathrm{ACh} 80 \mu \mathrm{g}$ & 3.2 & 3.8 & 1.5 & 1.5 & 2 & 1.7 & 2.2 \\
\hline
\end{tabular}

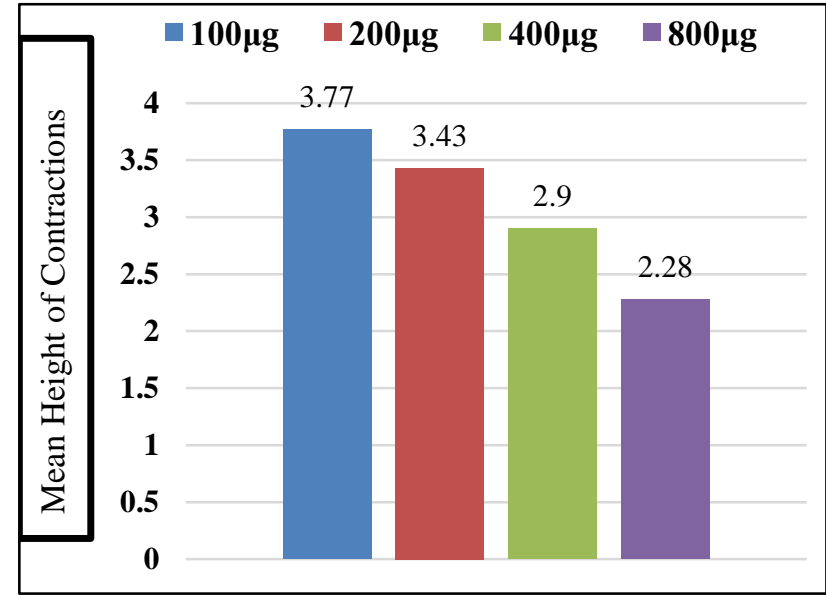

Figure 2: Comparison of mean height of contractions of frog rectus muscle at various doses of pheniramine maleate.

\section{DISCUSSION}

In the study of S.R.K. Acharya and Subba Rao, they reported the skeletal muscle relaxant action of antihistamines in rats. In this study, they tried 17 antihistamine drug effects on acetylcholine induced contractions of skeletal muscle.

The anticonvulsant action of dimethinedane in rats. ${ }^{4}$ Antihistamines are used as adjuvant in the treatments of paralytic agitans. Ramah and Lal reported a marked evaluation in Ach like activity in epileptic patients under electro convulsive therapy and migraine.

Acharya and Rao reported the inhibition of Acetylcholine like activity of scorpion venom on skeletal muscle by some of the antihistamines. ${ }^{2}$ In this study, the skeletal muscle relaxant property of $1^{\text {st }}$ generation antihistamine pheniramine maleate is evaluated and compared with 
control. This antihistamine drug shows the skeletal muscle relaxant property by decreasing the intracellular sodium and calcium ion concentrations. ${ }^{3}$

According to Law, the antihistamine drugs show the anticonvulsant, antiparkinsonian and anticholinergic effects, instead of their antihistaminic action. Because of all the studies done, it is said that these drugs are more effective, when used in combination with other drugs to potentiate or for additive effect.

Pheniramine Maleate at different doses such as $100 \mu \mathrm{g}$, $200 \mu \mathrm{g}, 400 \mu \mathrm{g}$ and $800 \mu \mathrm{g}$, shows statistically significant value when compared with control. Pheniramine maleate $100 \mu \mathrm{g}$ with $80 \mu \mathrm{g}$ of acetylcholine showed the maximum contractions of frog rectus muscle in kymograph. It showed the maximum relaxant effect on frog rectus muscle at $800 \mu \mathrm{g}$ dose.

\section{CONCLUSION}

This study was carried out to evaluate the skeletal muscle relaxant property of pheniramine maleate on frog rectus abdominus muscle by using kymograph. In conclusion with work done by using pheniramine maleate in different doses like $100 \mu \mathrm{g}, 200 \mu \mathrm{g}, 400 \mu \mathrm{g}$ and $800 \mu \mathrm{g}$ along with $80 \mu \mathrm{g}$ of acetylcholine. Pheniramine maleate showed the maximum skeletal muscle relaxant property on frog rectus muscle at $800 \mu \mathrm{g}$ dose. However, the above preclinical experiment only gives us an idea about the skeletal muscle relaxant property of pheniramine maleate.

\section{ACKNOWLEDGEMENTS}

Authors are very grateful to all the staff and students of Dept. of Pharmacology, Dr. PSIMS and RF for their help in this study.

\section{Funding: No funding sources}

Conflict of interest: None declared

Ethical approval: The study was approved by the Institutional Ethics Committee, Dr. PSIMS and RF

\section{REFERENCES}

1. Bertam G. Katzung Skeletal muscle relaxant, in Basic and Clinical Pharmacology, $13^{\text {th }}$ Edition; 2015:455.

2. Acharya SRK, Rao S. Action of scorpion venom on skeletal muscle and its antagonism by drugs, Arogya. J. Health Sciences; 1976:32:69-75.

3. Acharya SRK, Rao S. Action of chlorpromazine on the skeletal muscle of frog, current sciences. 1978:36:1479.

4. Chandra V. Anticonvulsant Activity of Demethindane Maleate, Indian Journal of Pharmacology. 1972:32:194-7.

5. Gonzalez MA, Estes KS. Pharmacokinetic overview of oral second-generation H1 antihistamine, International Journal of Clinical Pharmacology. 1998:36:292-300.

6. Randal A. Skidgel, Allen P. Kaplan Histamines and their antagonists, in Goodman and Gilman The Pharmacological Basis of Therapeutics, $12^{\text {th }}$ Edition; 2011:911.

7. Guyton and Hall, Neuromuscular transmission, Text book of Medical Physiology, 13 ${ }^{\text {th }}$ Edition; 2017:89-96.

8. Drugs used in treating motor disorders- pharmacology, in Rang HP, Dale MM Churchill Livingston London, $2^{\text {nd }}$ Edition; 1991:684-705.

9. Salter JW, Zechnich AD, Haxby DG. Secondgeneration antihistamines: A Comparative Review Drugs, J Allergy ClinImmunol. 1999:41:31-47.

10. Acharya SRK, Rao S. Comparative Study of Antihistamines on Skeletal Muscles, Indian Journal of Pharmacology. 1977:6:132-8.

11. Rajendar B, Venkatesham A, Bhavana K, Divya C, Swarna M, Anvesh K. Evalution Of Skeletal Muscle Relaxant Activity of Methanolic Leaf Extract of Moringa Oleifera World Journal of Pharmacy and Pharmaceutical Sciences. 2017;6(5):1095-102.

Cite this article as: Priyambada S, Lakshmi DP, Singamma M. The study of skeletal muscle relaxant property of pheniramine maleate in acetylcholine induced contractions on isolated frog rectus muscle. Int J Basic Clin Pharmacol 2018;7:396-9. 